5. Novikov, D. A. (2012). Theory of control of organizational systems. Moscow: Publisher physical and mathematical literature, 604 .

6. Ovsievich, B. L. (1979). Models of organizational structures. Leningrad: Scince, 160.

7. Rumyantseva, Z. P. (1997). Organizational Management. Moscow: Infra-M, 395.

8. Zykova, A. A. (1987). Fundamentals of graph theory. Moscow: Scince, 344.
9. Klevtsov, S. I., Klevtsova, A. B. (1999). Computer support of operational management in the organizational structures. Taganrog: Taganrog Radio Engineering University, 90.

10. Geras'kin, M. I. (2003). Formation of corporate management field system at several performance criteria based on graph controls. Proceedings of the Samara Scientific Center of the Russian Academy of Sciences, 3, 134-142.

Дата надходження рукопису 27.01.2015

Галіцин Володимир Костянтинович, доктор економічних наук, професор. кафедра інформаційного менеджменту. Київський національний економічний університет імені Вадима Гетьмана, Львівська площа, 14, м. Київ, Україна, 04053

E-mail: i42@kneu.kiev.ua

Суслов Олег Павлович, доктор економічних наук, професор, кафедра інформаційного менеджменту, Київський національний економічний університет імені Вадима Гетьмана. Львівська площа, 14, м. Київ, Україна, 04053

E-mail: suslov_@mail.ru

Остапчук Ольга Василівна, кандидат економічних наук. кафедра автоматизованих систем та моделювання в економіці. Хмельницький національний університет, вул. Кам'янецька, 110, м. Хмельницький, Україна, 29016

E-mail: z_olyska@ukr.net

УДК 2964

DOI: $10.15587 / 2313-8416.2015 .37213$

\title{
ОСОБЕННОСТИ РАЗВИТИЯ РЫНКА ЦЕННЫХ БУМАГ В АЗЕРБАЙДЖАНЕ
}

\author{
(C) Абдинов Рамиз Мобил оглы, Тагизаде Севиндж Сакит кызы
}

Наличие денег в национальной экономике приводит к формированию финансовой системы. Учитывая то, что главной функцией финансов является перераспределение, развитие финансовых рынков является основным условием механизма эффективного перераспределения. Финансовые рынки с целью нормального развития национальной экономики обеспечивают мобилизацию временно свободных денежных капиталов физических и юридических лии с коммерческой деятельности и распределение их между различными секторами экономики

Ключевые слова: иченная бумага, акция, облигачия, вексель, РЕПО и анти-РЕПО, клиринг, брокер, дилер, фондовая биржа, дивиденд, ноты, акционерные общества

The availability of money in the national economy leads to formation of financial system. Taking into account the fact that the main function of finance is redistribution, development of financial markets is an essential condition of effective redistribution mechanism. Financial markets to the normal development of the national economy provide the mobilization of temporarily free money capital of individuals and entities with commercial activities and their distribution among the various sectors of the economy

Keywords: securities, share, bonds, bills, repurchase agreement and anti-repurchase agreement, clearing, broker, dealer, stock exchange, dividend, notes, joint stock companies

\section{1. Введение}

Наличие денег в национальной экономике приводит к формированию финансовой системы. Учитывая то, что главной функцией финансов является перераспределение, развитие финансовых рынков является основным условием механизма эффективного перераспределения.

Рынок ценных бумаг состоит из первичного и вторичного рынков. На первичном рынке мобилизация финансовых ресурсов осуществляется за счёт выпуска ценных бумаг (эмиссия). В этом случае размещение ценных бумаг на рынке осуществляется двумя путями. В первом случае, размещающий ценные бумаги (эмитент) обращается непосредственно к инвесторам и путем распределения ценных бумаг между ними мобилизует финансовые средства. Во втором же случае, размещение (реализация) ценных бумаг осуществляется через посредников.

Ценные бумаги, размещённые на первичном рынке, покупаются и продаются на вторичном. В случае, когда первичный рынок является источником мобилизации средств для финансирования реального сектора, вторичный рынок, в основном, приводит к перераспределению богатства. Тем не менее, 
развитые вторичные рынки, выступая необходимым условием развития первичного рынка, являются важным фактором в обеспечении в стране эффективного распределения экономических ресурсов. Следует также отметить, что рынок ценных бумаг наряду с созданием дополнительных возможностей инвестиционных вложений в национальную экономику, а также финансирования производственнохозяйственной деятельности, погашает возникшие долги. Таким образом, такая ликвидность облегчает межотраслевое движение капитала и повышает её эффективность посредством рынка ценных бумаг. Влияние рынка ценных бумаг на развитие национальной экономики осуществляется различными инструментами, которые в свою очередь способствуют финансированию текущей деятельности и инвестиций.

\section{3. Текущее состояние развития ценных бумаг в Азербайджане \\ Развитие рынка ценных бумаг в Азербайджане} было, в основном, связано с приватизацией государственной собственности. Так, в процессе приватизации были выпущены приватизационные чеки и приватизационные опционы, являющиеся ценными бумагами, а средние и крупные предприятия были приватизированы путём преобразования в акционерные общества открытого типа. Количество предприятий, преобразованных на базе государственных в акционерные общества, за период с 1996 по 2013 гг. равно 1599 единицам, что и составляет основную часть акционерных обществ, созданных в стране. Часть таких акционерных обществ, примерно около 60,4 \%, были созданы в рамках I программы приватизации в 19951998 гг. Создание акционерных обществ в стране выявило необходимость в формировании инфраструктуры рынка ценных бумаг. Так в процессе приватизации была сформирована инфраструктура обеспечивающая учёт и оборот акций и приняты законодательные акты, регули-рующие данный процесс. Также в стране был сформирован неорганизованный рынок акций и приватизационных чеков. Формирование рынка ценных бумаг стало толчком для создания структуры регулирующей эту отрасль. По указу президента страны 30 декабря 1998го года был создан Государственный Комитет по Ценным Бумагам при Президенте Азербайджанской Республики. На сегодняшний день в Азербайджане была создана правовая база регулирующая рынок ценных бумаг, которая постоянно совершенствуется. Тем не менее, развитие данного рынка в большей степени зависит от административных факторов.

Как видно из данных табл. 1, оборот рынка ценных бумаг в стране в 2013-ом году по сравнению с 2010-ым годом увеличился в 3,8 раз. Тем не менее, этот рост, в основном, был обусловлен за счёт государственных ценных бумаг. Так, за упомянутый период, объём операций связанных с корпоративными ценными бумагами вырос в 2,2 раза, а для государственных ценных бумаг этот показатель был равен 4,7. В результате, в общем обороте рынка ценных бумаг в стране, доля государственных ценных бумаг возросла с $65,4 \%$ в 2010-ом г. до $80,3 \%$ в 2013-ом г.

Таблица 1

Оборот рынка ценных бумаг (млн.ман)

\begin{tabular}{|c|c|c|c|c|}
\hline & 2010 & 2011 & 2012 & 2013 \\
\hline Государственные ценные бумаги & 1523,0 & 6717,7 & 8093,7 & 7087,5 \\
\hline Корпоративные ценные бумаги & 805,7 & 2144,4 & 1328,8 & 1736,9 \\
\hline Всего & 2328,7 & 8862,0 & 9422,5 & 8824,4 \\
\hline
\end{tabular}

Примечание: таблица была составлена на основе данных Государственного Комитета по Ценным Бумагам

Как видно по данным табл. 2, за последние годы вторичный рынок способствовал росту объёма рынка ценных бумаг. Таким образом, в 2013 году объем рынка снизился примерно на $0,4 \%$ по сравнению с 2010 г., а объём вторичного рынка увеличился в 3,3 раза. Тем не менее, в 2013-ом г. доля первичного рынка в общем обороте первичного и вторичного рынков составила 52,7 \%. Это является следствием того, что рынок ценных бумаг не является одной из основных отраслей определяющих экономическую активность страны. Так, в развитых странах доля вторичного рынка в общем объёме рынка ценных бумаг значительна. На этом рынке, наряду со сделками по купле-продаже ценных бумаг между владельцами ценных бумаг, постоянно нуждающихся в деньгах и свободными владельцами капитала, постоянно совершаются спекулятивные сделки. И как результат, оборот вторичного рынка по сравнению с оборотом первичного больше.
Государственные ценные бумаги на местном рынке ценных бумаг состоят из государственных облигаций и нот Центрального банка. В соответствии с существующими правилами в стране могут быть выпущены государственные облигации и государственные казначейские векселя. Государственные ценные бумаги выпускаются для следующих целей [1].

- финансирование дефицита текущего бюджета;

- обеспечение выполнения по государственной кассе;

- регулирование последовательности бюджетных платежей;

- реализация предусмотренной государством денежно-кредитной политики;

- реализация программ экономического развития государственной важности;

- решение социальных проблем государственной важности. 
Таблица 2

Оборот ценных бумаг на первичном и вторичном рынках (млн. ман)

\begin{tabular}{|c|c|c|c|c|}
\hline & 2010 & 2011 & 2012 & 2013 \\
\hline Первичный рынок, всего & 1172,2 & 2449,2 & 1872,6 & 1167,0 \\
\hline В том числе: & & & & \\
\hline Государственные ценные бумаги & 583,1 & 881,6 & 1000,8 & 397,9 \\
\hline Корпоративные ценные бумаги & 589,1 & 1567,6 & 871,9 & 769,1 \\
\hline Вторичный рынок, всего & 318,8 & 630,9 & 693,4 & 1048,3 \\
\hline В том числе: & & & & \\
\hline Государственные ценные бумаги & 102,2 & 54,1 & 236,4 & 80,5 \\
\hline Корпоративные ценные бумаги & 216,6 & 576,7 & 456,9 & 967,8 \\
\hline Всего на первичном и вторичном рынках & 1491,1 & 3080,1 & 2566,0 & 2215,3 \\
\hline
\end{tabular}

Примечание: таблииа была составлена на основе данных Государственного Комитета по Ценным Бумагам

В настоящее время основная часть находящихся в обороте государственных ценных бумаг облигации. Эти ценные бумаги выпускаются, в основном, для обеспечения кассового исполнения бюджета. Тем не менее, в условиях обеспечения поступлений в государственный бюджет, в основном, за счёт средств Государственного Нефтяного Фонда исключается вероятность возникновения напряженности в выполнении бюджетной кассы.

Кроме того, широко используется банками такие ценные бумаги в качестве залога на краткосрочный период с целью привлечения свободных денежных средств. Таким образом, доходность ценных бумаг не допускает использовать их как инструмент для долгосрочных инвестиционных вложений.

С момента выпуска Министерством Финансов Азербайджана государственных ценных бумаг в обращение до сегодняшнего дня не наблюдалось непрерывного увеличения денежной массы в стране. В результате, не было необходимости покупки этих ценных бумаг со стороны Центрального Банка. Таким образом, с целью увеличения денежной массы в обращении Центральный Банк скупает государственные ценные бумаги, а для уменьшения продаёт. Центральный Банк не может пользоваться данным рычагом для уменьшения денежной массы, так как на его балансе нет ценных бумаг выпущенных Министерством Финансов.

Таблица 3

Объём сделок РЕПО/анти-РЕПО по ценным бумагам (млн. манат)

\begin{tabular}{|c|c|c|c|c|}
\hline & 2010 & 2011 & 2012 & 2013 \\
\hline РЕПО/анти-РЕПО & 837,7 & 5782,0 & 6856,5 & 6609,1 \\
\hline Государственные облигации (РЕПО/анти-РЕПО) & 29,3 & 17,5 & 4,5 & 12,2 \\
\hline Ноты Центрального Банка (РЕПО/анти-РЕПО) & 820,2 & 5752,7 & 6852,0 & 6596,9 \\
\hline
\end{tabular}

Примечание: таблииа была составлена на основе данных Государственного Комитета по Ценным Бумагам

Анализ, проведённый на основе сравнения табл. 1-3 показывает, что операции РЕПО и антиРЕПО занимают наибольший удельный вес в общем объёме операций производимых с ценными бумагами. Так, доля сделок РЕПО и анти-РЕПО в общем обороте ценных бумаг с 2010-го г. до 2013-го г. повысилась с 36,0\% до 74,9\%. Это показывает, что развитие рынка ценных бумаг связано с банковским сектором.

Следует отметить, что операции РЕПО и антиРЕПО используются Центральным банком для достижения целей в рамках денежной-кредитной политики и регулирования платежеспособности банковской системы. Операция РЕПО представляет собой продажу Центральным Банком ценных бумаг коммерческому банку (открытие РЕПО) и, в то же время, продажу тем самым банком купленных ценных бумаг Центральному Банку, со стороны Центрального Банка - финансовая операция формализующая обязательство по обратной куплепродаже (закрытие РЕПО). В операции анти-РЕПО процесс идёт в обратном направлении, т.е. в этом случае осуществляется продажа ценных бумаг Центральному Банку.
В последние годы, важную роль в увеличении объёма корпоративных облигаций на рынке ценных бумаг сыграл Ипотечный Фонд Азербайджана. Так, со стороны этого фонда на внутреннем рынке было размещено в 2009-ом г. облигаций на сумму в 55 млн. манат с гарантией на 7 лет и на сумму в 75 млн. манат с гарантией на 10 лет, в 2010-ом г. на сумму в 60,0 млн.манат с гарантией на 7 лет, в 2011-ом г.на сумму в 20,0 млн.манат с гарантией на 7 лет, в 2012-ом г. на сумму в 70,0 млн. манат с гарантией на 10 лет, в 2013-ом г. на сумму в 20,0 млн. манат с гарантией на 10 лет. Основную часть оборота на вторичном рынке составили операции, производимые с облигациями, данными финансовыми инструментами. Так, в 2013 г. доля корпоративных облигаций Ипотечного Фонда Азербайджана составила 85,9 \% в обороте корпоративных облигаций.

Таким образом, из проведённого анализа следует, что основную роль в формировании отечественного рынка ценных бумаг играют административные факторы.

Следует отметить, что, несмотря на относительное развитие в стране рынка выпускаемых ценных бумаг, рынок ценных бумаг, позволяющий 
ликвидировать долги, созданные коммерческими операциями, не развит. Одной из таких ценной бумаг является вексель. Вексель - это такая ценная бумага, которая представляет собой письменное обязательство, дающее владельцу векселя (векселедержателю) право на получение от должника по векселю определённой (указанной) в нём суммы по истечению срока обязательства. Одним из путей страхования от рисков экономических субъектов в стране является развитие дочернего (производного) рынка ценных бумаг. В Азербайджане, несмотря на наличие правил обращения фьючерсов, дочерний (производный) рынок ценных бумаг не развит [2]. Фьючерс - стандартизированный биржевой договор о покупке и продаже определенного базового актива в определенное время по заранее оговоренной цене. Другим видом производных ценных бумаг является опцион - договор, предоставляющий право его владельцу покупки и продажи базового актива в определенное время по заранее оговоренной цене. Варрант, обладая свойствами опциона, в отличие от него предоставляет право своему владельцу на покупку и продажу базового актива по заранее оговоренной цене в течение определенного периода.

Обеспечение развития ценных бумаг в стране требует формирования ряда необходимых условий. Одним из условий является формирование в стране необходимой инфраструктуры рынка ценных бумаг. Таким образом, инфраструктура рынка ценных бумаг связана с наличием двух групп участников. К первому из них относятся структуры, обеспечивающие движение ценных бумаг, ко второму непосредственно те структуры, которые проводят операции с ценными бумагами. В последние годы были предприняты важные шаги в направлении формирования инфраструктуры рынка ценных бумаг в Азербайджане.

15 февраля 2000-го г. была создана Бакинская Фондовая Биржа, являющаяся основой организованного рынка ценных бумаг в Азербайджане, как некоммерческая структура, впоследствии преобразованная в акционерное общество закрытого типа как коммерческая структура. На данный момент у биржи 20 акционеров. На БФБ есть торговый зал, состоящий из 30 рабочих мест и депозитарий, в котором осуществляется хранение и оборот ценных бумаг. Согласно статье 1078-15.6 Гражданского Кодекса размещение акций акционерных обществ методом массового предложения осуществляется посредством фондовой биржи. Несмотря на то, что данная статья была принята с целью развития фондовой биржи, она противоречит деятельности таких структур и принципам выпуска акций акционерными обществами. Так, для торговли ценными бумагами на бирже они должны попасть в листинг. Несмотря на наличие на БФБ требований котировочных листов 1-го и 2-го уровней, в этом списке числится всего лишь одно акционерное общество. Для того, чтобы ценные бумаги АО попали в листинг, они должны отвечать определенным требованиям. Другим важным фактором, определяющим введение компании в листинг, является наличие связей для переведения ценных бумаг в торговую систему биржи. Таким образом, для обеспечения торговли акциями АО на бирже между депозитарием обслуживающим биржу и реестродержателем реестра акционера должна быть установлена связь, посредством чего акции должны перейти в депозитарий. С другой стороны, АО не являются профессиональными участниками рынка ценных бумаг. С этой точки зрения первичный рынок ценных бумаг не осуществляется на фондовой бирже, фондовая биржа относится к вторичному рынку ценных бумаг. Таким образом, указанная статья Кодекса не только не способствует развитию фондовой биржи, но и приводит к искажению значения рынка ценных бумаг.

Следует отметить, что одним из факторов благоприятствующих созданию фондовой биржи в этой структуре является организация клиринга. Так, клиринг проведённых операций между участниками фондовой биржи, т.е. замена (компенсация), способствует как уменьшению текучести денег и ценных бумаг, так и уменьшению связанных с этим затрат.

Национальный Депозитарный Цент (НДЦ) в Азербайджане играют важную роль в формировании инфраструктуры рынка ценных бумаг. Эта структура является одной из первых структур, созданных на рынке ценных бумаг.

В общем, несмотря на рост числа профессиональных участников рынка ценных бумаг, масштаб и уровень профессионализма всё еще остается на низком уровне.

Один из факторов мешающих развитию рынка ценных бумаг в стране связан с защитой прав инвесторов и уровнем корпоративного управления. Корпоративное управление, в общем, это система отношений, обеспечивающая права и интересы участников заинтересованных в деятельности компании: между менеджментом компании и его владельцами; крупными пайщиками и мелкими; пайщиками, участвующими в управлении компанией и пайщиками, не участвующими в управлении. Обеспечение этих интересов зависит от формирования системы внутреннего и внешнего контроля.

Система, сформированная в стране, должна защищать права акционеров и создавать условия для реализации ими своих прав. Эта система должна обеспечить одинаковое и справедливое отношение ко всем акционерам, в том числе мелким пайщикам и тем, кто не участвует в управлении компанией.

\section{4. Выводы}

Таким образом, анализ показывает, что рост активности рынка ценных бумаг за последние годы, в основном, был обусловлен административными факторами. Несмотря на то, что на рынке ценных бумаг значительную часть ценных бумаг составляют государственные, они, в основном, состоят из нот и облигаций. Развитие корпоративного рынка ценных бумаг также, в основном, произошло за счёт административных факторов. Развитие рынка корпоративных облигаций осуществляется, в основном, посредством Ипотечного Фонда Азербайджана. 
Развитие рынка ценных бумаг - производная от развития реального сектора. Поэтому, структура и уровень развития национальной экономики являются одним из основных факторов определяющих основные тенденции развития рынка ценных бумаг.

\section{Литература}

1. Правила выпуска, размещения и циркуляции государственных и муниципальных ценных бумаг в Азербайджанской Республике [Текст] / Государственный Комитет по Ценным Бумагам при Президенте Азербайджанской Республики, 2000.

2. Правила циркуляции фьючерсов в Азербайджанской Республике [Текст] / Государственный Комитет по Ценным Бумагам при Президенте Азербайджанской Республики, 2001.

3. Гражданский Кодекс Азербайджанской Республики [Текст] / Статья 992-1.7 и 992-1.8.

4. Правила листинга, делистинга и торговли ценными бумагами на Бакинской Фондовой Бирже [Текст] / Бакинская Фондовая Биржа.

5. Правила проведения операций РЕПО и антиРЕПО с ценными бумагами Национальным Банком Азербайджанской Республики [Текст] / Государственный
Комитет по Ценным Бумагам при Президенте Азербайджанской Республики, 2001.

6. Закон Азербайджанской Республики «О банках» [Текст] / Статья 19.1.

\section{References}

1. Pravila vypuska, razmeshhenija i cirkuljacii gosudarstvennyh i municipal'nyh cennyh bumag v Azerbajdzhanskoj Respublike (2000). Gosudarstvennyj Komitet po Cennym Bumagam pri Prezidente Azerbajdzhanskoj Respubliki.

2. Pravila cirkuljacii fjuchersov v Azerbajdzhanskoj Respublike (2001). Gosudarstvennyj Komitet po Cennym Bumagam pri Prezidente Azerbajdzhanskoj Respubliki.

3. Grazhdanskij Kodeks Azerbajdzhanskoj Respubliki. Stat'ja 992-1.7 i 992-1.8.

4. Pravila listinga, delistinga i torgovli cennymi bumagami na Bakinskoj Fondovoj Birzhe. In: Bakinskaja Fondovaja Birzha.

5. Pravila provedenija operacij REPO $i$ anti-REPO $s$ cennymi bumagami Nacional'nym Bankom Azerbajdzhanskoj Respubliki (2001). Gosudarstvennyj Komitet po Cennym Bumagam pri Prezidente Azerbajdzhanskoj Respubliki. Stat'ja 19.1

6. Zakon Azerbajdzhanskoj Respubliki «O bankah».

Рекомендовано до публікаиії д-р екон. наук, професор профессор Гасанов Р. Т. Дата надходження рукопису 23.01.2015

Абдинов Рамиз Мобил оглы, кандидат экономических наук, доцент, кафедра «Экономика и менеджмент», Азербайджанская Государственная Нефтяная Академия, ул. Кадырли, 75, г. Баку, Азейрбаджан, AZ106

Тагизаде Севиндж Сакит кызы, диссертант, Азербайджанская Государственная Нефтяная Академия, ул. Кадырли, 75, г. Баку, Азейрбаджан, AZ106

E-mail: qezale@mail.ru

УДК 332.334.4.: 631.618

DOI: $10.15587 / 2313-8416.2015 .37803$

\section{ДЕЯКІ МЕТОДОЛОГІЧНІ АСПЕКТИ ЕКОЛОГО-ЕКОНОМІЧНОЇ ОЦІНКИ РЕКУЛЬТИВАЦІЇ ПОРУШЕНИХ ЗЕМЕЛЬ}

\section{(C). І. Галаган}

Доведено, щзо ціна землі, яка вилучається із сільськогосподарського виробництва для видобутку корисних копалин складається з ціни значущості землі як компонента природи, з ціни землі як основного засобу виробництва, з ціни на відновлення колишньої родючості та з ціни на поліпшення екологічного стану довкілля. На основі агротехнічних характеристик гірських порід показані галузі економіки їх подальшого використання

Ключові слова: техногенний ландшафт, рекультивація порушених земель, иіна землі, витрати, чистий дохід

It is proved that the price of land that is taken out of agricultural production for mining operations consists of the price of the importance of land as a component of nature, the price of the land as the main means of production, price to restore fertility and price of improvement of the ecological status of environment. Based on the agronomic characteristics of rocks there are shown the industries of their further use

Keywords: technogenic landscape, recultivation of disturbed lands, land price, costs, net income

\section{1. Вступ}

Наразі під впливом виробничої діяльності людини відбуваються грандіозні зміни як живої, так і неживої природи. Особливо під час видобутку мінеральної сировини, що призводить до руйнації динамічної рівноваги в природних екосистемах та до погіршення екологічного стану навколишнього середовища.

Реалії сьогодення свідчать про те, що техногенний прес на довкілля зростає 3 кожним роком і одним з його головних наслідків $є$ створення несприятливих для людини санітарно-гігієнічних 